\section{(- \\ OPEN ACCESS}

\title{
Late diagnosis: a case of rapidly progressive extranodal NK/T cell lymphoma, nasal type
}

\author{
Hiroyuki Mori, ${ }^{1}$ Kei Ebisawa, ${ }^{1}$ Mitsushige Nishimura, ${ }^{2}$ Kenji Kanazawa ${ }^{3}$
}

${ }^{1}$ Department of General Internal Medicine, Kobe University Hospital, Kobe, Hyogo, Japan ${ }^{2}$ Internal Medicine, Nishiizu Kenikukai Hospital, Kamo, Shizuoka, Japan ${ }^{3}$ General Internal Medicine, Kakogawa Chuo Shimin Hospital, Kakogawa, Hyogo, Japan

\section{Correspondence to} Dr Hiroyuki Mori, himori@med.kobe-u.ac.jp

Accepted 26 January 2018

\section{SUMMARY}

Extranodal natural killer (NK)/T cell lymphoma, nasal type is a condition that has poor prognosis. Accurate diagnosis of lymphoma is made by pathological findings. We report a case of extranodal NK/T cell lymphoma, nasal type affecting the lung and liver and which was difficult to diagnose because of negative biopsy results from multiple sites. A 39-year-old man who had dry cough and fever for 1 month was referred to our hospital. He had pancytopenia and elevated serum levels of lactate dehydrogenase and soluble interleukin-2 receptor. Hepatosplenomegaly and multiple lung nodules were found on imaging study. Specimens of bronchoscopic lung, percutaneous liver, bone marrow and random skin biopsies were all negative. Open lung biopsy was not definitive. Unfortunately, disease progression was rapid and fatal before results of pleural fluid cytology and a second liver biopsy showed extranodal NK/T cell lymphoma, nasal type. This report focused on diagnostic planning for rapidly progressive extranodal NK/T-cell lymphoma, nasal type.

\section{BACKGROUND}

Biopsy is an essential approach to the diagnosis of lymphoma. When a suspected disease is known to progress rapidly, a plan for further investigation must be made in case the initial biopsy specimen turns out negative. A plan for a more invasive procedure should also be considered if the non-invasive procedure is not useful.

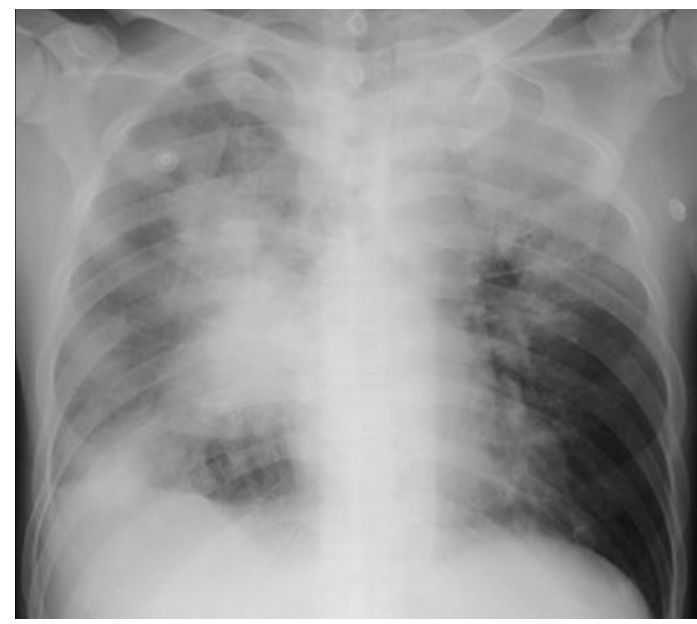

Figure 1 Chest X-ray showing multiple nodular lesions bilaterally.

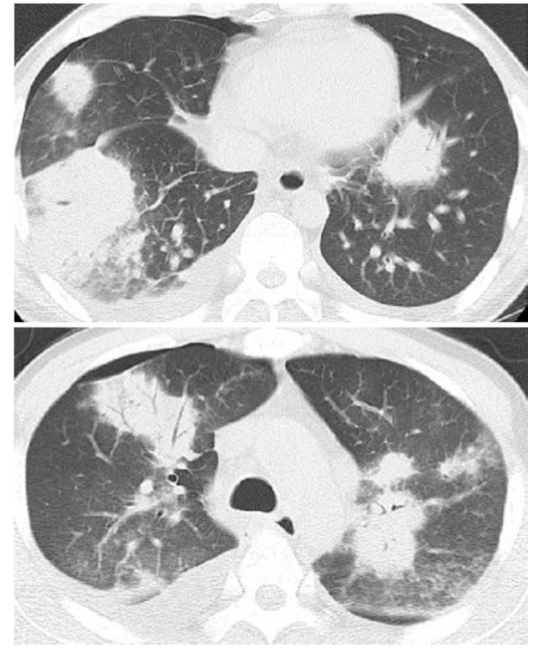

Figure 2 Chest CT imaging showing multiple nodular lesions bilaterally.

Here, we present a case of extranodal NK/T cell lymphoma, nasal type that took time to make a final pathological diagnosis. In addition, we reviewed eight previously reported cases of primary pulmonary NK/T cell lymphoma on the point of view of diagnosis. ${ }^{1-8}$ Among these cases, two were diagnosed by postmortem examination. ${ }^{56}$ Oshima et al reported one case in which bronchoscopic biopsy and CT-guided needle biopsy were unable to yield a definite diagnosis. ${ }^{5}$ Laohaburanakit et al reported another case in which pleural fluid examination and CT-guided needle biopsy were non-diagnostic. ${ }^{6}$

Biopsies of the lung by bronchoscopy and open approach, bone marrow, liver by percutaneous needle aspiration and skin did not give a definitive diagnosis for our patient. Finally, pleural fluid examination and a second liver biopsy gave the diagnosis, but after his death. On hindsight, it is noteworthy that once the clinical status of a patient deteriorates, more invasive procedures for biopsy cannot be performed. Therefore, aggressive planning for biopsy is crucial to make diagnosis of extranodal NK/T cell lymphoma, nasal type.

\section{CASE PRESENTATION}

A 39-year-old man complained of cough, loss of appetite and fever for 2 weeks. He was admitted in another hospital and was treated as pneumonia with ampicillin-sulbactam for $12 \mathrm{~g} /$ day for 4 days and meropenem $3 \mathrm{~g} /$ day for 3 days. However, his clinical status did not improve; blood and sputum cultures did not grow any pathogens. Thereafter, 


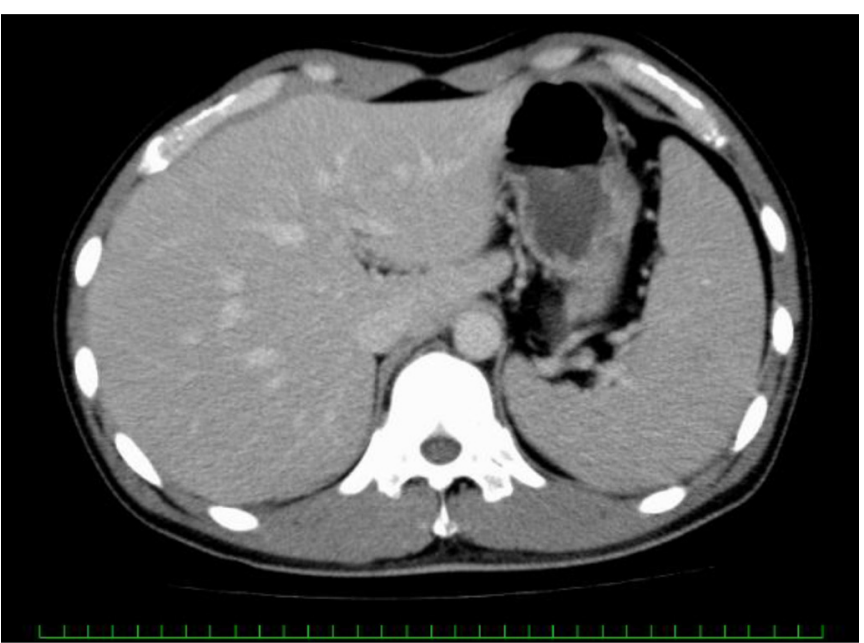

Figure 3 Abdominal CT imaging showing hepatosplenomegaly.

he was transferred to another hospital for further investigation. Multiple bilateral nodules were found on chest CT imaging. Cefepime $4 \mathrm{~g} /$ day and clindamycin $1.8 \mathrm{~g} /$ day were administered for 3 days. Bronchoscopy showed no macroscopically abnormal findings. Transbronchial biopsy of the consolidated lung lesion showed only lung necrosis. He was referred to our hospital 1 month after the onset of symptoms.

He had a medical history of cough-variant asthma without medications. He had a travel history to the USA and Hong Kong over 10 years ago. He did not drink alcohol and was a current smoker (400 pack-years). He had worked as delivery person for more than 15 years. His father had gastric cancer at the age of 65 years and was currently in remission. He did not have any other remarkable family history.

On admission, blood pressure was $126 / 84 \mathrm{~mm} \mathrm{Hg}$, pulse rate was 98 beats $/ \mathrm{min}$, body temperature was $39^{\circ} \mathrm{C}$ and respiratory rate was $26 / \mathrm{min}$. Oxygen saturation was $94 \%$ at $4 \mathrm{~L} / \mathrm{min}$ of oxygen support per face mask. Physical examination revealed hepatosplenomegaly, but there were no lymphadenopathy and abnormal respiratory sound.

\section{INVESTIGATIONS}

Laboratory findings showed white cell count 2000/ $\mu \mathrm{L}$, haemoglobin $12 \mathrm{~g} / \mathrm{dL}$, platelet count $66000 / \mu \mathrm{L}$, aspartate aminotransferase 199 IU/L (normal: 13-31 IU/L), alanine aminotransferase
97 IU/L (normal: 8-34 IU/L), lactate dehydrogenase (LDH) $1850 \mathrm{IU} / \mathrm{L}$ (normal: 115-217 IU/L) and soluble interleukin-2 receptor (sIL-2r) 2170 U/mL (normal: 145-519U/mL). Circulating Epstein-Barr virus-DNA load was not obtained. Nasopharyngoscopy showed no evidence of lymphoma. Multiple nodular lesions were seen on chest X-ray (figure 1) and CT scan (figure 2). Hepatosplenomegaly was present on abdominal CT imaging (figure 3), but there was no lymphadenopathy on chest and abdominal CT scans.

Percutaneous liver biopsy on the first day of admission, random skin biopsy on the fifth day and bone marrow biopsy on the fifth day were all negative for malignant cells. Thoracentesis could not be performed due to the small amount of pleural effusion. An open lung biopsy was then performed on the seventh day; the small amount of pleural fluid was also submitted for pathological examination at the same time. A day after, a second percutaneous liver biopsy was performed while waiting for the result of lung biopsy, which eventually showed angiodestructive necrotic tissues. After his death, results of pleural fluid cytology and the second liver biopsy showed lymphoma (figure 4A,B). On immunohistochemical staining, atypical cells were positive for CD3, CD56 and Epstein- Barr encoding region (EBER), but negative for CD20 (figure 5). These findings were consistent with extranodal NK/T cell lymphoma, nasal type.

\section{DIFFERENTIAL DIAGNOSIS}

A man was referred to our hospital for cough, loss of appetite and fever that lasted for more than 1 month. He had multiple nodular lesions on both lung fields and hepatosplenomegaly on CT imaging. Complete blood count showed pancytopenia. Metabolic panel showed elevated liver enzymes, LDH and sIL-2r. Our differential diagnoses were malignant lymphoma, sarcoidosis, intracellular infection (mycobacterium, legionella and nocardiosis), invasive fungal infection and Leishmaniasis. However, the latter is not prevalent in Japan and the patient did not visit any country where Leishmaniasis is prevalent. To arrive at a definitive diagnosis among the diseases considered, tissue biopsy for pathology and culture is the mainstay. We finally reached a diagnosis of extranodal NK/T cell lymphoma, nasal type from pleural fluid analysis and second liver biopsy.

\section{TREATMENT}

After admission to our hospital, ceftriaxone $2 \mathrm{~g} /$ day and azithromycin $500 \mathrm{mg} /$ day were initiated. However, his clinical status did
A

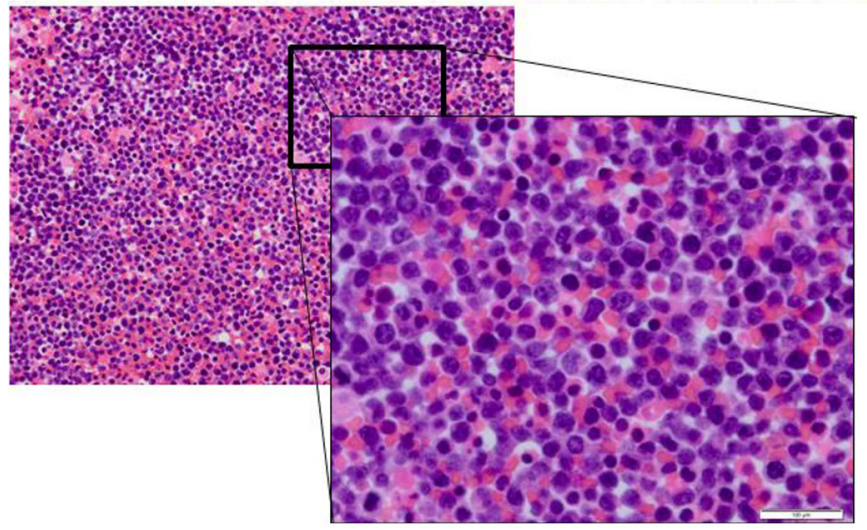

B

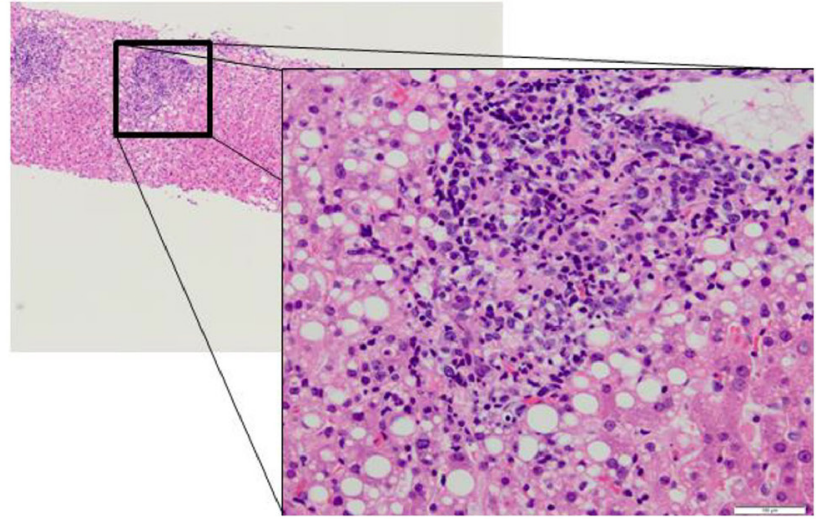

Figure 4 (A) Pleural effusion micropathology showing immature lymphocytes with irregular karyotype. (B) Liver micropathology showing immature lymphocytes with irregular karyotype. 


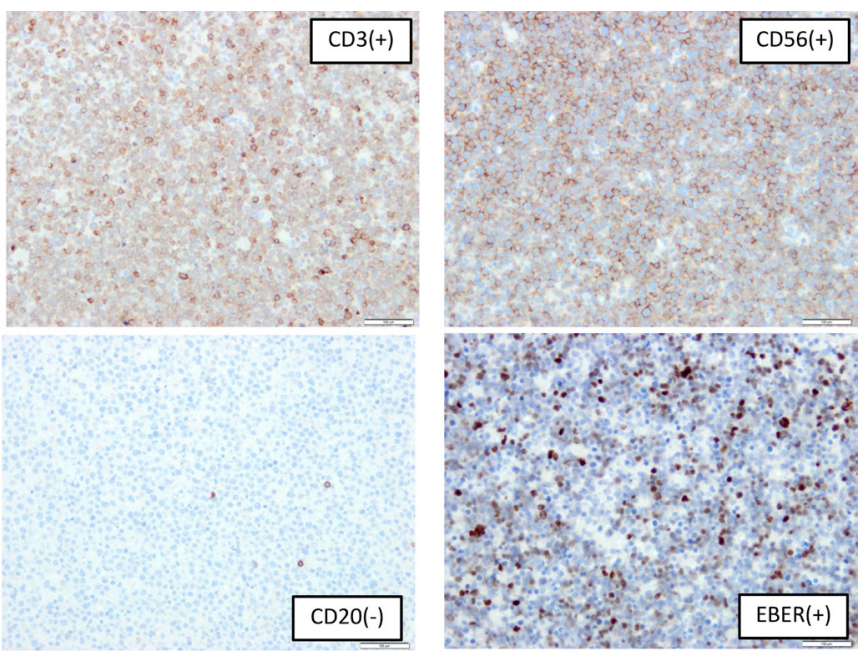

Figure 5 Immunohistochemical staining of pleural effusion showing positive for CD3, CD56 and Epstein-Barr encoding region (EBER), but negative for CD20.

not improve. In addition, vancomycin $1 \mathrm{~g}$ /day and minocycline $200 \mathrm{mg} /$ day were initiated on the third day of admission. Liposomal amphotericin B was added to cover for invasive fungal infection. However, due to rapid deterioration and non-response to antibiotics, we strongly suspected a diagnosis of malignant lymphoma; therefore, glucocorticoid therapy $(60 \mathrm{mg} /$ day then $100 \mathrm{mg} /$ day) was initiated on the fifth day of admission.

\section{OUTCOME AND FOLLOW-UP}

On the fourth day of admission, the clinical status of the patient deteriorated. Mechanical ventilation was started for dyspnoea and hypoxaemia. He died on the eighth day of admission. After his death, a diagnosis of extranodal NK/T cell lymphoma, nasal type was made from examination of the pleural effusion and second liver biopsy.

\section{DISCUSSION}

Extranodal NK/T cell lymphoma, nasal type is more common in Asia than in Europe and the USA. One report showed that among 136 cases of extranodal NK/T cell lymphoma, 68\% was of the nasal type and only $26 \%$ was of the extranasal type; of the two types, the latter has a worse prognosis. ${ }^{9}$ The preferential sites of extranasal involvement are the skin, gastrointestinal tract, testis and soft tissue; primary lung involvement is rare. Ko et al ${ }^{10}$ reported that extranodal CD56+, EBV- NK/T cell lymphoma at extranasal sites was a clinically less aggressive malignancy and displays less necrosis than the CD56+, EBV+ variant, which our patient had. One report showed eight cases of primary pulmonary NK/T cell lymphoma, including seven previously reported cases. ${ }^{1}$ In this report, five of eight primary pulmonary NK/T cell lymphoma cases showed angiocentric or angiodestructive growth pattern with extensive necrosis on histology. In our present case, lung biopsy did not show lymphoma cells, but showed angiodestructive pattern and extensive necrosis.

Using the key word 'primary pulmonary NK/T cell lymphoma' for PubMed search, we included eight case reports written in English and excluded one case report written in Chinese. ${ }^{11}$ Among the eight cases with primary pulmonary NK/T cell lymphoma, only one was reported to have successful treatment. ${ }^{1-8}$ Diagnoses were made by bronchoscopic biopsy in three cases ${ }^{128}$ : CT-guided needle biopsy in two cases, ${ }^{37}$ pleural fluid analysis in one case ${ }^{4}$ and postmortem examination in two cases. ${ }^{56}$ Oshima et al reported one case in which bronchoscopic biopsy and CT-guided needle biopsy did not give a definite diagnosis. ${ }^{5}$ Likewise, Laohaburanakit et al reported another case in which pleural fluid examination and CT-guided needle biopsy were non-diagnostic. ${ }^{6}$ These two cases were diagnosed by postmortem examination.

In three out of nine cases, including our case, arriving at a diagnosis was difficult despite multiple biopsies from different sites. Usually, a biopsy plan is made from a non-invasive procedure to a more invasive approach. However, if a rapidly progressive disease like extranodal NK/T cell lymphoma, nasal type is suspected, one should not wait to do an invasive biopsy procedure until the results of the other non-invasive biopsy specimens come out.

Our patient died of lymphoma one and half month after the onset of symptoms. Percutaneous liver biopsy, bone marrow biopsy, skin biopsy and open lung biopsy were performed within 8 days. Finally, pleural effusion and liver biopsy specimens showed lymphoma. Open lung biopsy, pleural fluid cytology and second liver biopsy were performed after the initiation of glucocorticoid treatment. However, because final diagnosis was made by the pleural fluid cytology and second liver biopsy, only the result of open lung biopsy, which was turned out to be negative, may be influenced by glucocorticoid therapy. One case report showed that NK/T cell lymphoma may present as pleural effusion. ${ }^{12}$ Based on this experience, we should bear in mind that pleural effusion could be a good specimen for the diagnosis of extranodal NK/T cell lymphoma, nasal type. In this case, we performed liver biopsy two times; the second showed lymphoma, but the first one was non-diagnostic. Even if a diagnosis cannot be made from initial pathological analysis, another specimen from the same organ should be obtained repeatedly.

\section{Learning points}

- If a rapidly progressive disease like extranodal natural killer (NK)/T cell lymphoma, nasal type is suspected, one should not wait to do further invasive biopsy procedures until the results of other non-invasive biopsy specimens come out.

- Pleural effusion could be a good specimen for the diagnosis of extranodal NK/T cell lymphoma, nasal type. In this case, we could not perform thoracentesis due to the small amount of pleural effusion. Instead, we obtained the pleural effusion during open lung biopsy.

- If a diagnosis cannot be made from one pathological analysis, another specimen from the same organ should be obtained repeatedly.

Contributors All persons who meet all four ICMJE authorship criteria are listed as authors, and all authors certify that they have participated sufficiently in the work to take public responsibility for the content, including participation in the concept, design, analysis, writing, or revision of the manuscript. Furthermore, each author certifies that this material or similar material has not been and will not be submitted to or published in any other publication before its appearance in the BMJ case report. MN was involved in the acquisition of data. HM and MN were involved in the analysis and interpretation of data. HM drafted the manuscript. KE, MN and KK revised the manuscript critically for important intellectual content. All authors contributed to the conception and design of the case report, approval of the version of the manuscript to be published and agreed to be accountable for all aspects of the work in ensuring that questions related to the accuracy or integrity of any part of the work are appropriately investigated and resolved.

Competing interests None declared.

Patient consent Parental consent obtained.

Provenance and peer review Not commissioned; externally peer reviewed. 
Open Access This is an Open Access article distributed in accordance with the Creative Commons Attribution Non Commercial (CC BY-NC 4.0) license, which permits others to distribute, remix, adapt, build upon this work non-commercially, and license their derivative works on different terms, provided the original work is properly cited and the use is non-commercial. See: http://creativecommons.org/ licenses/by-nc/4.0/

(c) BMJ Publishing Group Ltd (unless otherwise stated in the text of the article) 2018. All rights reserved. No commercial use is permitted unless otherwise expressly granted.

\section{REFERENCES}

1 Chien CC, Lee HS, Lin MH, et al. Primary extranodal natural killer/T-cell lymphoma of bronchus and lung: a case report and review of literature. Thorac Cancer 2016;7:140-4.

2 Lee $\mathrm{S}$, Shin $\mathrm{B}$, Yoon $\mathrm{H}$, et al. A case of primary pulmonary NK/T cell lymphoma presenting as pneumonia. Respir Med Case Rep 2016;17:1-4.

3 Liu CH, Wang HH, Perng CL, et al. Primary extranodal NK/T-cell lymphoma of the lung: mimicking bronchogenic carcinoma. Thorac Cancer 2014;5:93-6.

4 Mizuki M, Ueda S, Tagawa S, et al. Natural killer cell-derived large granular lymphocyte lymphoma of lung developed in a patient with hypersensitivity to mosquito bites and reactivated epstein-barr virus infection. Am J Hematol 1998;59:309-15.

5 Oshima K, Tanino Y, Sato S, et al. Primary pulmonary extranodal natural killer/T-cell lymphoma: nasal type with multiple nodules. Eur Respir J 2012;40:795-8.

6 Laohaburanakit P, Hardin KA. NK/T cell lymphoma of the lung: a case report and review of literature. Thorax 2006;61:267-70.

7 Lee BH, Kim SY, Kim MY, et al. CT of nasal-type T/NK cell lymphoma in the lung. J Thorac Imaging 2006;21:37-9.

8 Gui W, Yang B, Shen Q, et al. Successful treatment with L-asparaginase-based regimen for primary pulmonary NK/T cell lymphoma: a case report and review of the literature. Clin Respir J 2015;9:493-6.

9 Au WY, Weisenburger DD, Intragumtornchai T, et al. Clinical differences between nasal and extranasal natural killer/T-cell lymphoma: a study of 136 cases from the international peripheral T-cell lymphoma project. Blood 2009;113:3931-7.

$10 \mathrm{Ko} \mathrm{YH}$, Cho EY, Kim JE, et al. NK and NK-like T-cell lymphoma in extranasal sites: a comparative clinicopathological study according to site and EBV status. Histopathology 2004;44:480-9.

11 Cao MS, Cai HR, Yin HL, et al. [Primary natural killer/T cell lymphoma of the lung: two cases report and clinical analysis]. Zhonghua Jie He He Hu Xi Za Zhi 2008;31:120-4.

12 Liu F, Lin YH, Liu HX, et al. Natural killer/T cell lymphoma initiating with pleural effusion: the significance of MICM combined techniques for the diagnosis. Zhongguo Shi Yan Xue Ye Xue Za Zhi 2009;17:1347-51.

Copyright 2018 BMJ Publishing Group. All rights reserved. For permission to reuse any of this content visit

http://group.bmj.com/group/rights-licensing/permissions.

BMJ Case Report Fellows may re-use this article for personal use and teaching without any further permission.

Become a Fellow of BMJ Case Reports today and you can:

- Submit as many cases as you like

- Enjoy fast sympathetic peer review and rapid publication of accepted articles

- Access all the published articles

- Re-use any of the published material for personal use and teaching without further permission

For information on Institutional Fellowships contact consortiasales@bmjgroup.com

Visit casereports.bmj.com for more articles like this and to become a Fellow 